\title{
Low cycle fatigue behavior of ITER-like divertor target under DEMO-relevant operation conditions
}

\author{
Muyuan $\mathrm{Li}^{\mathrm{a}}$, Ewald Werner ${ }^{\mathrm{a}}$, Jeong-Ha You ${ }^{\mathrm{b}, *}$ \\ ${ }^{a}$ Lehrstuhl für Werkstoffkunde und Werkstoffmechanik, Technische Universität München, Boltzmannstr.15, 85748 Garching, \\ Germany \\ ${ }^{b}$ Max-Planck-Institut für Plasmaphysik, Boltzmannstr.2, 85748 Garching, Germany
}

\begin{abstract}
In this work the low cycle fatigue (LCF) behavior of the copper alloy cooling tube and the copper interlayer of an ITER-like divertor target is reported for nine different combinations of loading and cooling conditions relevant to DEMO divertor operation. The LCF lifetime is presented as a function of loading and cooling conditions considered here by means of cyclic plasticity simulation and using LCF data of materials relevant for ITER. The numerical predictions indicate, that fatigue failure will not be an issue for the copper alloy tube under a high heat flux (HHF) load of up to $18 \mathrm{MW} / \mathrm{m}^{2}$ as long as it preserves its initial strength. In contrast, the copper interlayer exhibits significant plastic dissipation at the free surface edge of the bond interface adjacent to the cooling tube, where the LCF lifetime is predicted to be below 3000 load cycles for HHF loads higher than $15 \mathrm{MW} / \mathrm{m}^{2}$. Most of the bulk region of the copper interlayer away from the free surface edge does not experience severe plastic fatigue and hence does not pose any critical concern as the LCF lifetime is predicted to be at least 7000 load cycles. LCF lifetime decreases as HHF load is increased or coolant temperature is decreased.
\end{abstract}

Keywords: divertor, low cycle fatigue, finite element method

\section{Introduction}

The inner and outer vertical target plate has the highest thermal loading of the divertor cassette and thus has to be actively cooled by a coolant in long pulse fusion operation. According to the latest 'Work plan of the European roadmap for fusion power', a water-cooled divertor is foreseen as the primary design option for the $1^{\text {st }}$ generation DEMO reactor [1, 2]. The decision in favor of water-cooling is mainly owing to the superior heat removal capability of the water-cooled target concept compared with a helium-cooled counterpart. This feature is an essential advantage in efforts to enhance the power exhaust capacity of a power plant. Furthermore, the engineering of a water-cooled target can profit from the mature technology readiness level that may be attributed to the ample $R \& D$ experience accumulated in the ITER project. For this reason, an ITER-like divertor target design is currently considered as one of the initial reference models for the DEMO divertor [3]. The ITER divertor target is characterized as a serial array of rectangular tungsten monoblocks connected by a copper alloy cooling tube running through the central region of the monoblocks. Here, the cooling tube is the only structural member whereas the plasma-facing tungsten

\footnotetext{
${ }^{*}$ Corresponding author. Tel.: +49 (0)89 3299 1373; fax:+49 (0)89 32991212.

Email address: you@ipp.mpg.de (Jeong-Ha You)
} 
armor is regarded as functional part. This means that the target design has to fulfill the requirements of a structural design code for the cooling tube.

Recently, an extensive design-to-code study has been conducted by a research group at ENEA for an ITER-like target design assuming DEMO-relevant loading and cooling conditions (heat flux: $10 \mathrm{MW} / \mathrm{m}^{2}$, coolant temperature: $200^{\circ} \mathrm{C}$, coolant pressure: $5 \mathrm{MPa}$ ) [3]. This study showed that the ITER-like target with an optimized geometry could pass the elastic structural design criteria of the ITER SDC-IC code provided that the applied kinematic constraints are statically determinate [3, 4]. It turned out that the cooling tube of the ITER-like target could just pass the $3 S_{\mathrm{m}}$ criterion of the $\mathrm{C}$ type (cyclic) load category indicating that progressive plastic deformation (ratchetting) might be the most critical failure mode. On the other hand, the low cycle fatigue (LCF) lifetime of the tube, which was predicted using S-N curve data, was estimated to reach at least 40000 load cycles. It is noted that the copper alloy used was a precipitation-hardened $\mathrm{CuCrZr}$ while soft pure copper was considered for the stress-relieving interlayer.

Since the design study mentioned above was carried out under consideration of elastic design criteria, the results may have some limitation in accuracy, in particular, in the prediction of LCF or ratchetting failure. To achieve a more realistic assessment of LCF or ratchetting behavior of the copper alloy tube, one needs to employ a rigorous constitutive model to capture cyclic plasticity. This requirement becomes even more critical when the highly ductile copper interlayer needs to be evaluated additionally in terms of its structural integrity, although it does not directly carry the applied primary loads [5, 6]. A further technical complication arises in the code-based design study due to the temporal variation of the temperature field during fabrication as well as heat flux loading. Elastic stress analysis has a further weakness in computing the thermal stresses of a brazed joint structure. The latter issue is mainly related to the difficulty to define an effective stress free temperature for the joint system on a reasonable mechanics basis. The problems can be reduced significantly by means of a cyclic plasticity simulation and assuming a realistic thermal history that the target component would undergo.

The aim of this contribution is to investigate the LCF or ratchetting behavior of the ductile members of an ITER-like divertor target model, namely, copper alloy cooling tube and copper interlayer, for a wide range of DEMO-relevant operation conditions. Quantitative assessment of LCF lifetime is presented for nine different combinations of loading and cooling conditions.

\section{FE model}

\subsection{Geometry, FE mesh and materials}

The monoblock type divertor target model has already been applied to the water-cooled divertor target of ITER. Furthermore, it was also considered for the water-cooled divertor target of a fusion power plant in the framework of the Power Plant Conceptual Study (model A: WCLL) 7]. The monoblock target consists of a number of small rectangular tungsten blocks which are connected by a long cooling tube of a high thermal conductivity metal (e.g. copper alloy) running through the central region of each block, see Fig. 1 Two neighboring blocks are separated by a thin gap $(\sim 0.3 \mathrm{~mm})$. The deposited heat is transported from the surface to the cooling tube through the tungsten block. The block functions as sacrificing armor whereas the tube acts as heat sink. The typical dimensions of a block are roughly $20 \times 20 \times 3-5 \mathrm{~mm}$, and the tube has an inner diameter of $10 \mathrm{~mm}$ ( $1 \mathrm{~mm}$ wall thickness). The distance from the loading surface to the tube is determined by the predicted erosion rate and the envisaged erosion lifetime. At the brazed bond interface between the tungsten block and the copper alloy tube, a thin $(\sim 0.5 \mathrm{~mm})$ interlayer of soft copper is placed in order to reduce the residual or the thermal stress.

The plasma facing component (PFC) model considered for the FEM study is a water-cooled tungsten monoblock duplex structure consisting of a tungsten armor block and a copper alloy cooling tube (heat sink). The geometry, the finite element (FE) mesh and the constituent materials of the considered model PFC are shown in Fig. 2 The tungsten armor block has dimensions of $23 \times 22 \times 4 \mathrm{~mm}$. The cooling tube has a thickness of $1.0 \mathrm{~mm}$ and an inner diameter of $12 \mathrm{~mm}$. The thickness of the copper interlayer is $0.5 \mathrm{~mm}$. The geometry used here is based on the optimization of the geometry of the ITER tungsten divertor [3]. The commercial FEM code ABAQUS was employed for the numerical studies using quadratic brick elements of 


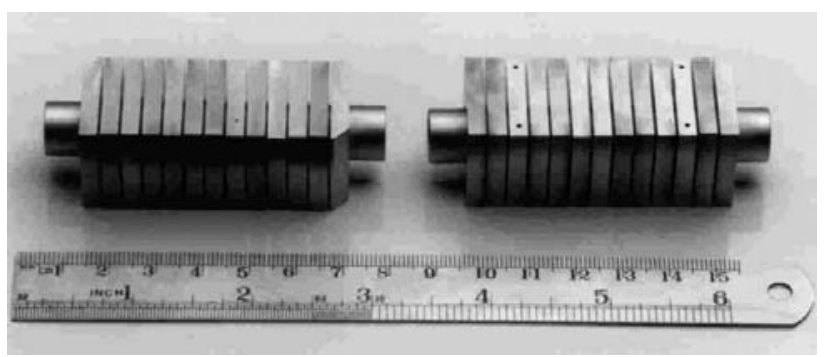

Fig. 1. Picture of representative mock-ups with 13 tungsten blocks [8].

20 nodes each. In total, there were 8496 finite elements. The mesh in the critical region of the component was refined.

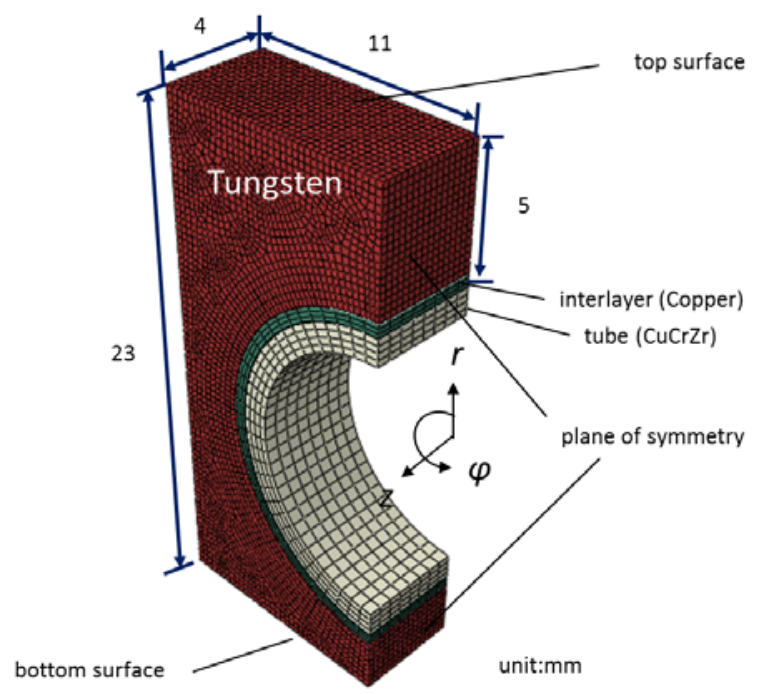

Fig. 2. The FE mesh of the monoblock divertor model. Due to symmetry only one half of the structure was considered.

The thermo-mechanical elasto-plastic simulations are based on data of several materials in the PFC model. Cross-rolled and stress-relieved tungsten was applied for the tungsten armor block. In the simulation tungsten was assumed to behave linearly elastic and ideally plastic. A precipitation-hardened copper alloy $(\mathrm{CuCrZr})$ was considered for the heat sink tube and soft-annealed copper constituted the interlayer. The Frederick-Armstrong constitutive model applied for copper and the copper alloy is based on the combination of non-linear isotropic and kinematic hardening laws [9 11]. Temperature-dependent material properties are listed in Table 1 1at selected temperatures, corresponding to the operation temperatures for the considered materials. It should be noted that the materials are assumed to be unirradiated due to lack of data of irradiated materials.

\subsection{Loads and boundary conditions}

The thermal history assumed for the present simulation considers the whole temperature changes to be generated by fabrication process as well as HHF loading and standby state.

The actual fabrication process of the ITER-like divertor target can be schematically modelled as consisting of 1) uniform cooling from the joining temperature $\left(900^{\circ} \mathrm{C}\right)$ to room temperature $\left.(\mathrm{RT}), 2\right)$ uniform heating from $\mathrm{RT}$ to $450^{\circ} \mathrm{C}$ which simulates the ageing heat treatment for precipitation hardening, 3) uniform 
Table 1. Properties of the considered materials at selected temperatures [4, 12].

\begin{tabular}{lccccccc}
\hline \hline & \multicolumn{3}{c}{ Tungsten $^{1}$} & \multicolumn{2}{c}{$\mathrm{CuCrZr}^{2}$} & \multicolumn{2}{c}{$\mathrm{Copper}^{3}$} \\
\hline & $20{ }^{\circ} \mathrm{C}$ & $40{ }^{\circ} \mathrm{C}$ & $1200^{\circ} \mathrm{C}$ & $20{ }^{\circ} \mathrm{C}$ & $400{ }^{\circ} \mathrm{C}$ & $20{ }^{\circ} \mathrm{C}$ & $400{ }^{\circ} \mathrm{C}$ \\
\hline Young's modulus (GPa) & 398 & 393 & 356 & 115 & 106 & 115 & 95 \\
Yield stress (MPa) & 1385 & 1100 & 346 & 273 & 238 & 3 & 3 \\
$Q^{*}(\mathrm{MPa})$ & & & & -43 & -68 & 76 & 36 \\
$b^{*}$ & & & & 6 & 10 & 8 & 25 \\
$C^{*}(\mathrm{MPa})$ & & & & 148575 & 117500 & 64257 & 31461 \\
$\gamma^{*}$ & 175 & 140 & 105 & 318 & 347 & 379 & 352 \\
Heat conductivity $(\mathrm{W} / \mathrm{mK})$ & 170 & & & & & \\
Coefficient of & & & & & & & \\
thermal expansion $\left(10^{-6} / \mathrm{K}\right)$ & 4.5 & 4.6 & 5.3 & 16.7 & 17.8 & 17.8 & 18.1 \\
\hline
\end{tabular}

1 Rolled and stress-relieved state.

${ }^{2}$ Precipitation-hardened state, the reference alloy: Elmedur-X (code: $\mathrm{CuCr} 1 \mathrm{Zr}, \mathrm{Cr}: 0.8 \%, \mathrm{Zr}: 0.08 \%$ ).

3 Softened by annealing at $700{ }^{\circ} \mathrm{C}$ for $1 \mathrm{~h}$.

* Material parameters entering the Frederick-Armstrong constitutive model [12].

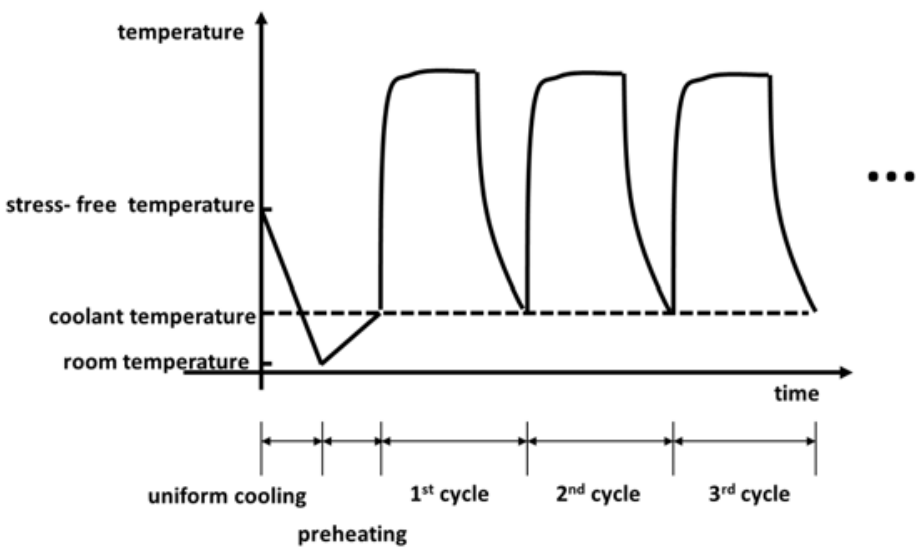

Fig. 3. Schematic drawing of the thermal excursion of the PFC.

cooling from the ageing temperature $\left(450^{\circ} \mathrm{C}\right)$ to $\left.\mathrm{RT}, 4\right)$ uniform heating from RT to the coolant temperature which corresponds to preheating of the component with warm water, and finally, 5) HHF loading followed by cooling phase. The step 1) was neglected in the stress analysis as solution annealing would take place at $900{ }^{\circ} \mathrm{C}$ leading to significant loss of strength in the $\mathrm{CuCrZr}$ alloy tube and thus producing only weak residual stress. The step 2) was also neglected in the stress analysis, since the weak initial residual stress produced by previous cooling would be mostly removed during the heat treatment by annealing effect. On the contrary, the $\mathrm{CuCrZr}$ alloy tube becomes essentially strengthened by the precipitation hardening at the ageing temperature. Thus, one can expect that considerable thermal stress will be produced during subsequent cooling to RT due to the mismatch in thermal contraction. This thermal stress forms the initial residual stress of the joint component. Therefore, in this study, the thermal history stages ranging from step 3) to step 5) (as shown in Fig. (3) were considered for the stress analysis where $450{ }^{\circ} \mathrm{C}$ (ageing temperature) was assumed to be stress-free temperature (i.e. the reference temperature for strain calculation). In total, 10 HHF load cycles are simulated for step 5). Each cycle includes $30 \mathrm{~s}$ of HHF loading and $10 \mathrm{~s}$ of cooling. Based on the thermal simulation using the finite element method, the PFC is cooled completely to the coolant temperature at the end of cooling. Thus the temperature variation in each cycle is identical.

The heat transfer coefficient between the inner wall of the heat sink tube and the coolant water is plotted 
in Fig. 4 The pressure of the coolant water is $5 \mathrm{MPa}$. The displacement of the end cross-sections of the tube is fully fixed in the tube axis direction, as the tube is assumed to have infinite length. The bottom surface of the PFC is fixed in vertical direction. This full constraint boundary condition is taken as an extreme case to gain a conservative prediction (i.e. higher stress in the tungsten block due to this constraint).

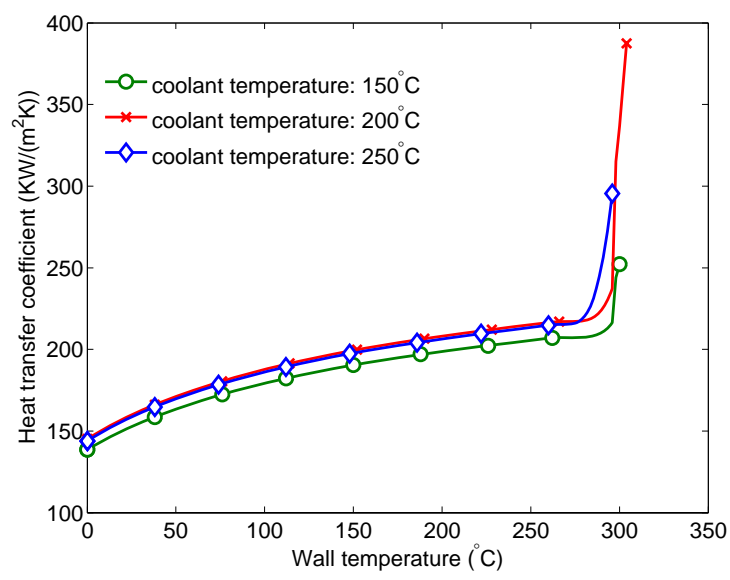

Fig. 4. Heat transfer coefficient between the inner wall of the heat sink tube and the coolant water.

\section{Results and discussion}

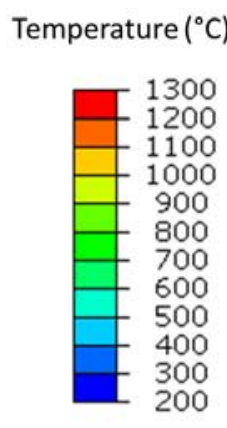

Position 1 (in the tungsten block)

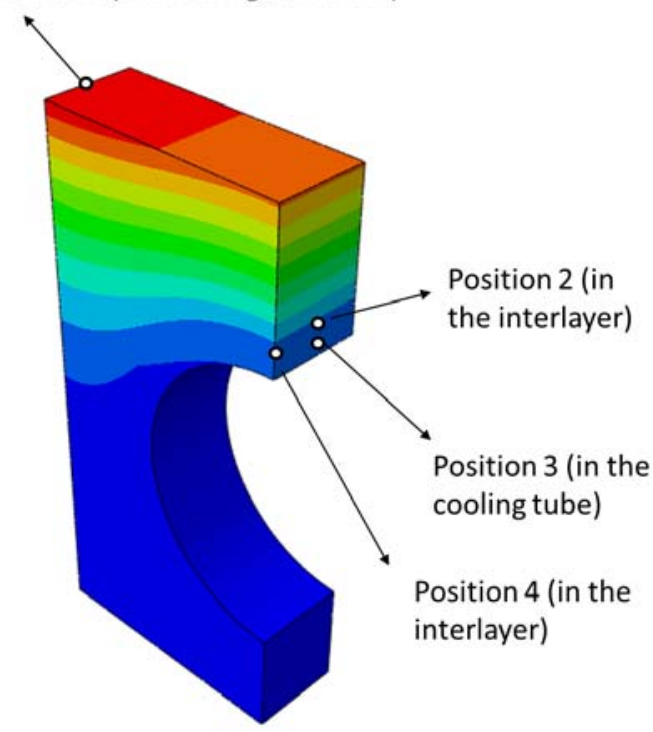

Fig. 5. Temperature field at the end of HHF loading for an HHF load of $15 \mathrm{MW} / \mathrm{m}^{2}$ and a coolant temperature of $200{ }^{\circ} \mathrm{C}$.

In order to cover DEMO-relevant operation conditions, thermal simulations were performed for loading and cooling combinations of HHF loads of $10 \mathrm{MW} / \mathrm{m}^{2}, 15 \mathrm{MW} / \mathrm{m}^{2}$ and $18 \mathrm{MW} / \mathrm{m}^{2}$ and coolant temperatures of $150{ }^{\circ} \mathrm{C}, 200^{\circ} \mathrm{C}$ and $250^{\circ} \mathrm{C}$. Fig. 5 shows the temperature field at the end of HHF loading for an HHF 
load of $15 \mathrm{MW} / \mathrm{m}^{2}$ and a coolant temperature of $200{ }^{\circ} \mathrm{C}$. The upper part of the divertor is heated up by HHF loads, while the lower part is nearly not influenced. The peak temperature at the top surface is close to $1300^{\circ} \mathrm{C}$, while the temperature in the interlayer and the cooling tube is below $400{ }^{\circ} \mathrm{C}$.

Table 2. Peak temperatures $\left({ }^{\circ} \mathrm{C}\right.$; the amplitude of temperature change $\left[{ }^{\circ} \mathrm{C}\right]$ in an $\mathrm{HHF}$ load cycle) at positions 1,2 and 3 (see Fig. 5. for different HHF loads and coolant temperatures.

\begin{tabular}{lccc}
\hline coolant temperature $\left({ }^{\circ} \mathrm{C}\right)$ & 150 & 200 & 250 \\
\hline HHF loads $\left(\mathrm{MW} / \mathrm{m}^{2}\right)$ & & & \\
\hline Position 1 & 820 & 879 & 924 \\
10 & 1221 & 1279 & 1315 \\
15 & 1478 & 1531 & 1562 \\
18 & & & \\
\hline Position 2 & $283.6(133.6)$ & $329.0(129.0)$ & $357.3(100.3)$ \\
10 & $347.3(197.3)$ & $383.0(183.0)$ & $400.0(150.0)$ \\
15 & $385.5(235.5)$ & $415.8(215.8)$ & $428.7(178.7)$ \\
18 & & & \\
\hline Position 3 & $262.8(112.8)$ & $308.1(108.1)$ & $335.7(85.7)$ \\
10 & $316.1(166.1)$ & $351.3(151.3)$ & $367.5(117.5)$ \\
15 & $348.2(198.2)$ & $378.0(178.0)$ & $390.3(140.3)$ \\
18 & & &
\end{tabular}

To characterize the temperature evolution in each part with respect to loading and cooling conditions, three reference positions (positions 1,2 and 3) are selected where the maximum temperature occurs, see Fig. 5 Position 4 is in the interlayer adjacent to the cooling tube at the free edge. Table 2 lists the peak temperature and the amplitude of temperature change in an HHF load cycle at positions 1, 2 and 3 for different $\mathrm{HHF}$ loads and coolant temperatures. The peak temperature at the top surface ranges from $820^{\circ} \mathrm{C}$ to $1562{ }^{\circ} \mathrm{C}$, while the temperature in the interlayer and the cooling tube is below $450{ }^{\circ} \mathrm{C}$. The amplitude of temperature change in an $\mathrm{HHF}$ load cycle is between $80^{\circ} \mathrm{C}$ and $200^{\circ} \mathrm{C}$ in the interlayer and the cooling tube. The peak temperature in the interlayer is higher than that in the cooling tube, and the amplitude of temperature change is larger too. When the power density of HHF loads increases, both the peak temperature and the amplitude of temperature change increase. If a higher coolant temperature is applied, the peak temperature is higher, but the amplitude of temperature change is smaller. As a result, the largest amplitude of temperature change in an HHF load cycle occurs for an HHF load of $18 \mathrm{MW} / \mathrm{m}^{2}$ and a coolant temperature of $150^{\circ} \mathrm{C}$ among the studied nine combinations of HHF loads and coolant temperatures.

Due to the high yield stress of tungsten, there is nearly no plastic deformation generated in the tungsten block during HHF loading, while the interlayer is expected to experience severe incremental plastic straining due to the low yield stress of copper. Figs. 60 and 8 show plastic strain fields of the interlayer and the cooling tube at the $10^{\text {th }}$ HHF load cycle for an HHF load of $15 \mathrm{MW} / \mathrm{m}^{2}$ and a coolant temperature of $200^{\circ} \mathrm{C}$. Cylindrical coordinates with their origin at the center of the tube on the plane of the right endcrosssection of the tube are applied for the plots, see Fig. 2 No significant discrepancy exists between the plastic deformations at the lower and the upper parts of the interlayer or the cooling tube, although the temperature in the lower part is hardly influenced by the HHF loads. This is because that compared to the plastic deformation generated in the uniform cooling and the preheating steps, the plastic deformation induced by HHF loading and cooling is smaller, since the temperature variation in the uniform cooling and preheating steps is larger than in an HHF load cycle. For the same reason, the difference between plastic strains at the end of HHF loading and at the end of cooling is insignificant, too. Figs. 9 and 10] show the evolution of plastic strain at positions 2 and 3 as a function of the number of HHF load cycles. Each curve denotes one of the plastic strain components. All three components show a cyclic variation in the interlayer with saturation amplitudes (no ratchetting), while no plastic deformation is generated during HHF loading in the cooling tube. The plastic strain evolution in the interlayer clearly indicates an LCF situation. Table 3 lists the minimum and the maximum values of the three plastic strain components at positions 2 and 4 at 


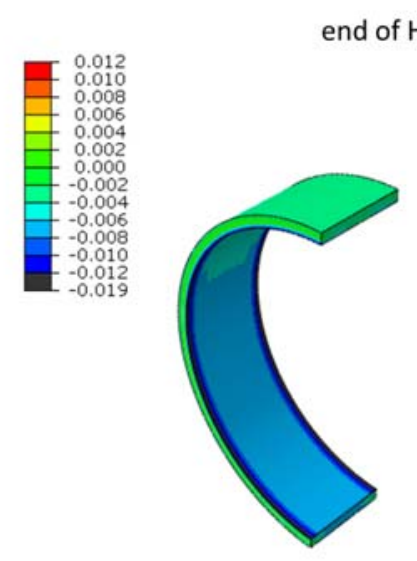

interlayer

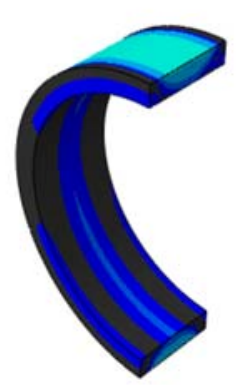

tube

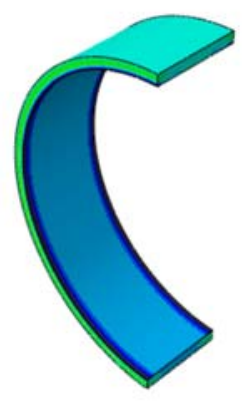

interlayer

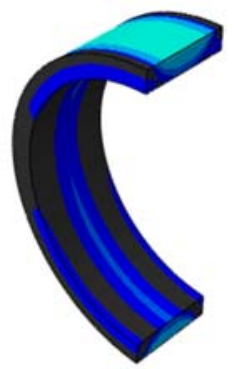

tube

Fig. 6. Plastic strain field in radial direction at the $10^{\text {th }}$ HHF load cycle for an HHF load of $15 \mathrm{MW} / \mathrm{m}^{2}$ and a coolant temperature of $200^{\circ} \mathrm{C}$.

the $10^{\text {th }}$ HHF load cycle for different loading and cooling conditions. Position 4 is selected to characterize the plastic strain concentration in the interlayer close to the cooling tube at the free surface edge.

Most of the LCF data in the literature are obtained from a uniaxial cyclic loading tests. The cooling tube or the interlayer in the divertor target is loaded by multi-axial stresses. Thus, for the assessment of the LCF lifetime, the multi-axial plastic strain data must be converted into scalar values so that the simulation result can be directly compared with the measured data. To this end, the equivalent plastic strain [13], $\varepsilon_{\mathrm{eq}}^{\mathrm{pl}}$, is used:

$$
\varepsilon_{\mathrm{eq}}^{\mathrm{pl}}=\sqrt{\frac{2}{3} \varepsilon_{i j}^{\mathrm{pl}} \varepsilon_{i j}^{\mathrm{pl}}}
$$

where $\varepsilon_{i j}^{\mathrm{pl}}$ is the plastic strain component. The accumulated equivalent plastic strain is defined as $\int_{0}^{t} \dot{\varepsilon}_{\mathrm{eq}}^{\mathrm{pl}} \mathrm{d} t$, where $\dot{\varepsilon}_{\mathrm{eq}}^{\mathrm{pl}}$ is the rate of equivalent plastic strain and $t$ is time.

Fig. 11 shows the accumulated equivalent plastic strain for an HHF load of $15 \mathrm{MW} / \mathrm{m}^{2}$ and a coolant temperature of $200^{\circ} \mathrm{C}$ at the end of the $10^{\text {th }} \mathrm{HHF}$ load cycle. The accumulated equivalent plastic strain in the cooling tube is negligible compared to that in the interlayer, since no plastic deformation is generated in the cooling tube during HHF loading. The cross-section of the cooling tube is fixed in axial direction assuming an infinite length of the cooling tube, while no constraint is applied at the side surface of the interlayer. As a result, the plastic strain is concentrated in the interlayer at the free surface edge of the bond interface adjacent to the cooling tube. In Figs. 12] and [13, the evolution of the accumulated equivalent plastic strain at position 2 and 4 (see Fig. 11) are plotted for different loading and cooling conditions. Due to the plastic strain concentration, the accumulated equivalent plastic strain is larger at position 4 than at position 2. When a larger HHF load is applied, the accumulated equivalent plastic strain increases, while it decreases as coolant temperature increases. The cyclic increment of the accumulated equivalent plastic strain is nearly saturated within 10 cycles for all load cases. The range of equivalent plastic strain is estimated from half of the increment of the accumulated equivalent plastic strain at $10^{\text {th }}$ HHF load cycle.

Fig. 14 shows the experimental fatigue test data 14] of pure copper (OFHC) including both high cycle (elastic) and low cycle (plastic) fatigue regimes. The Manson-Coffin type relationship proposed in the ITER Materials handbook [14] was used to fit the experimental fatigue test data, 

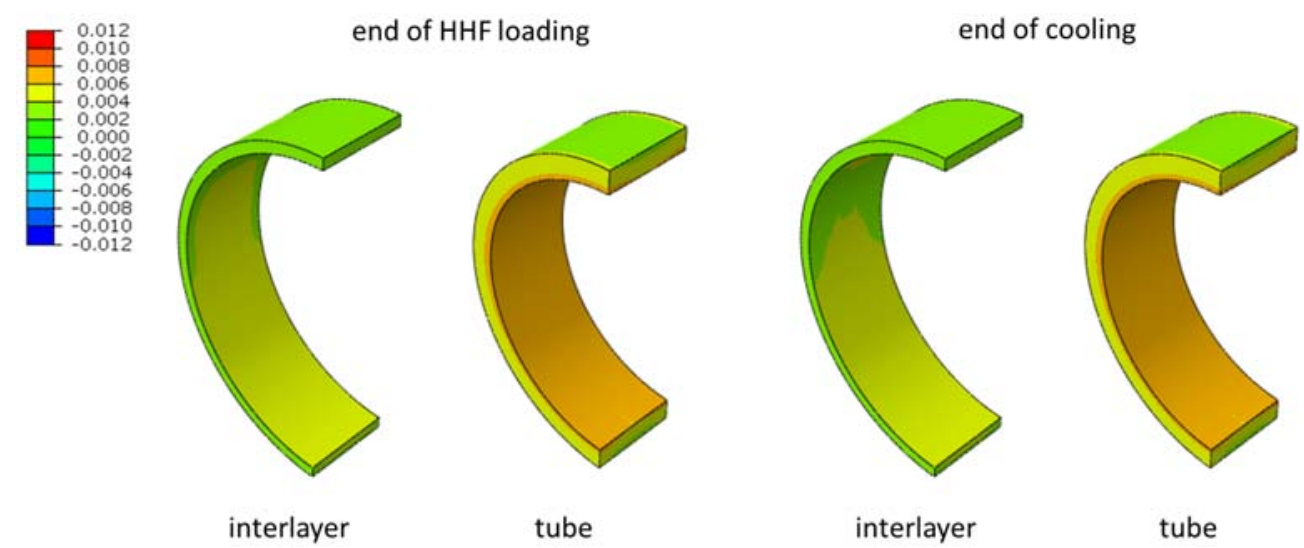

Fig. 7. Plastic strain field in hoop direction at the $10^{\text {th }}$ HHF load cycle for an HHF load of $15 \mathrm{MW} / \mathrm{m}^{2}$ and a coolant temperature of $200^{\circ} \mathrm{C}$.

$$
\Delta \varepsilon_{\mathrm{t}}=\underbrace{49.89 N_{\mathrm{f}}^{-0.57}}_{\text {plastic }}+\underbrace{0.40 N_{\mathrm{f}}^{-0.075}}_{\text {elastic }}
$$

where $\Delta \varepsilon_{\mathrm{t}}$ is the total strain range, $N_{\mathrm{f}}$ is the cycles to failure.

As in the LCF regime, the contribution from the plastic component is dominant, only the LCF part (that is, the plastic term) of the equation was considered in the present assessment of the LCF lifetime. The equivalent plastic strain range was used instead of the total strain range. A design fatigue curve was deduced from the fitted strain-life relation for the plastic component by offsetting the fit by a factor of 10 in the number of cycles to failure. The design curve is well below most of the fatigue data reported in the references, see Fig. 14

Table 4 lists the predicted equivalent plastic range at the $10^{\text {th }}$ HHF load cycle as well as the LCF lifetime of the interlayer. The LCF lifetime is estimated only for the interlayer, but not for the cooling tube, as the copper alloy in the cooling tube shakes down already in the first HHF load cycle and thus undergoes no further plastic deformation during the cyclic HHF loading stage posing no critical issues on LCF. The shortest LCF lifetime of the copper is predicted to be less than 1000 cycles at the free surface edge of the bond interface adjacent to the cooling tube, which is less than the technology qualification requirement of a full-tungsten divertor (approximately 5000 cycles for $10 \mathrm{MW} / \mathrm{m}^{2}$ ) [15]. It should be noted that the fatigue data for unirradiated copper in the ITER Material Properties Handbook is based on the tests between $20^{\circ} \mathrm{C}$ and $300^{\circ} \mathrm{C}$, which is lower than the current temperature of most loading combinations. There is no significant temperature dependency of fatigue lifetime blow $300^{\circ} \mathrm{C}$, however, a few tests show that the fatigue lifetime at 400 or $500^{\circ} \mathrm{C}$ is shorter in the low cycle regime than that obtained from low temperature tests [14], which indicates the predicted LCF lifetime at position 4 can be even shorter. This critical situation occurs only in a limited domain, where the plastic strain is concentrated, see Fig. 11, The predicted LCF lifetime at position 2 is much longer than that at position 4 , and hence fulfills the technology qualification requirement of a full-tungsten divertor. However, for a conservative prediction using the design curve, the predicted LCF lifetime in Table 4 should be divided by 10 as was mentioned above, and thus the interlayer will not fulfill the requirement. To ensure the reliability of the PFCs, relevant experiments are suggested. 


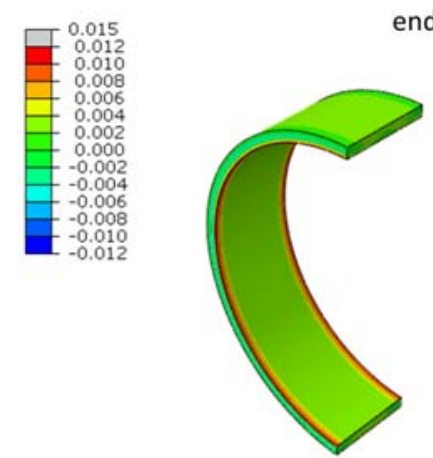

interlayer end of HHF loading

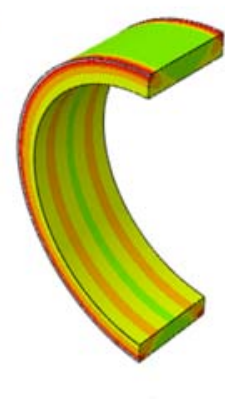

tube

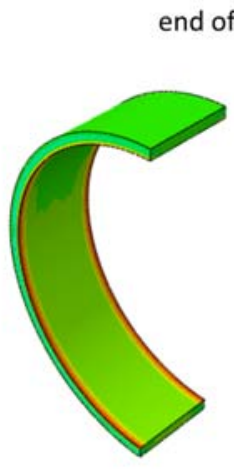

interlayer

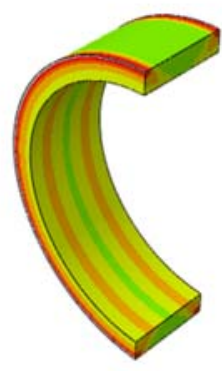

tube

Fig. 8. Plastic strain field in axial direction at the $10^{\text {th }} \mathrm{HHF}$ load cycle for an HHF load of $15 \mathrm{MW} / \mathrm{m}^{2}$ and a coolant temperature of $200^{\circ} \mathrm{C}$.

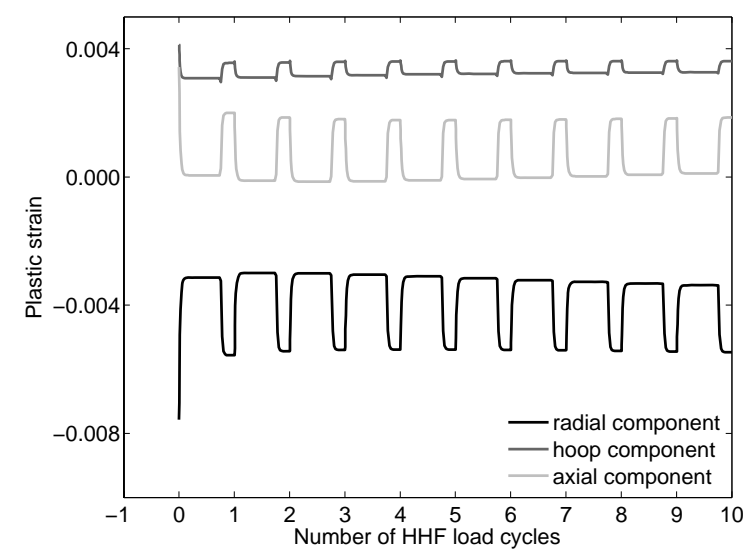

Fig. 9. Evolution of plastic strain at position 2 (see Fig. (5) for an $\mathrm{HHF}$ load of $15 \mathrm{MW} / \mathrm{m}^{2}$ and a coolant temperature of $200^{\circ} \mathrm{C}$. 


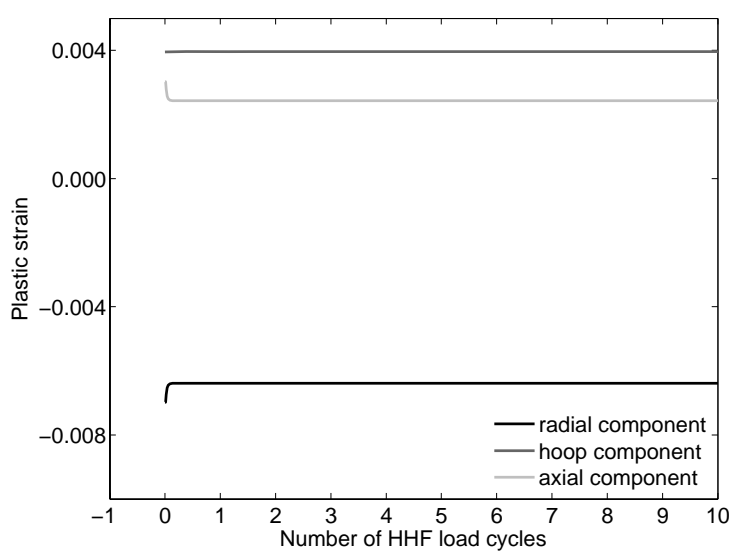

Fig. 10. Evolution of plastic strain at position 3 (see Fig. 5) for an HHF load of $15 \mathrm{MW} / \mathrm{m}^{2}$ and a coolant temperature of $200^{\circ} \mathrm{C}$.

Table 3. Minimum \maximum values (\%) of the three plastic strain components at positions 2 and 4 at the $10^{\text {th }}$ HHF loading, as shown in Fig. 11

\begin{tabular}{|c|c|c|c|}
\hline coolant temperature $\left({ }^{\circ} \mathrm{C}\right)$ & 150 & 200 & 250 \\
\hline \multicolumn{4}{|l|}{ HHF loads $\left(\mathrm{MW} / \mathrm{m}^{2}\right)$} \\
\hline \multicolumn{4}{|l|}{ Position 2} \\
\hline \multicolumn{4}{|l|}{ in radial direction } \\
\hline 10 & $-0.65 \backslash-0.52$ & $-0.56 \backslash-0.42$ & $-0.45 \backslash-0.35$ \\
\hline 15 & $-0.61 \backslash-0.37$ & $-0.55 \backslash-0.34$ & $-0.46 \backslash-0.30$ \\
\hline 18 & $-0.59 \backslash 0.30$ & $-0.55 \backslash-0.29$ & $-0.47 \backslash-0.28$ \\
\hline \multicolumn{4}{|l|}{ in hoop direction } \\
\hline 10 & $0.38 \backslash 0.42$ & $0.33 \backslash 0.36$ & $0.29 \backslash 0.31$ \\
\hline 15 & $0.37 \backslash 0.42$ & $0.32 \backslash 0.36$ & $0.29 \backslash 0.31$ \\
\hline 18 & $0.36 \backslash 0.42$ & $0.32 \backslash 0.36$ & $0.29 \backslash 0.31$ \\
\hline \multicolumn{4}{|l|}{ in axial direction } \\
\hline 10 & $0.13 \backslash 0.24$ & $0.09 \backslash 0.19$ & $0.06 \backslash 0.14$ \\
\hline 15 & $0.00 \backslash 0.19$ & $0.01 \backslash 0.19$ & $0.01 \backslash 0.15$ \\
\hline 18 & $-0.06 \backslash 0.18$ & $-0.03 \backslash 0.19$ & $-0.02 \backslash 0.17$ \\
\hline \multicolumn{4}{|l|}{ Position 4} \\
\hline \multicolumn{4}{|l|}{ in radial direction } \\
\hline 10 & $-1.64 \backslash-1.40$ & $-1.53 \backslash-1.30$ & $-1.40 \backslash-1.24$ \\
\hline 15 & $-1.67 \backslash-1.25$ & $-1.57 \backslash-1.20$ & $-1.44 \backslash-1.20$ \\
\hline 18 & $-1.66 \backslash-1.14$ & $-1.58 \backslash-1.14$ & $-1.46 \backslash-1.16$ \\
\hline \multicolumn{4}{|l|}{ in hoop direction } \\
\hline 10 & $0.41 \backslash 0.45$ & $0.35 \backslash 0.39$ & $0.31 \backslash 0.32$ \\
\hline 15 & $0.39 \backslash 0.47$ & $0.35 \backslash 0.40$ & $0.31 \backslash 0.33$ \\
\hline 18 & $0.38 \backslash 0.47$ & $0.33 \backslash 0.40$ & $0.30 \backslash 0.33$ \\
\hline \multicolumn{4}{|l|}{ in axial direction } \\
\hline 10 & $\begin{array}{l}0.98 \backslash 1.19 \\
\end{array}$ & $0.95 \backslash 1.15$ & $0.93 \backslash 1.08$ \\
\hline 15 & $0.85 \backslash 1.21$ & $0.85 \backslash 1.17$ & $0.88 \backslash 1.11$ \\
\hline 18 & $0.76 \backslash 1.20$ & $0.81 \backslash 1.19$ & $0.85 \backslash 1.14$ \\
\hline
\end{tabular}



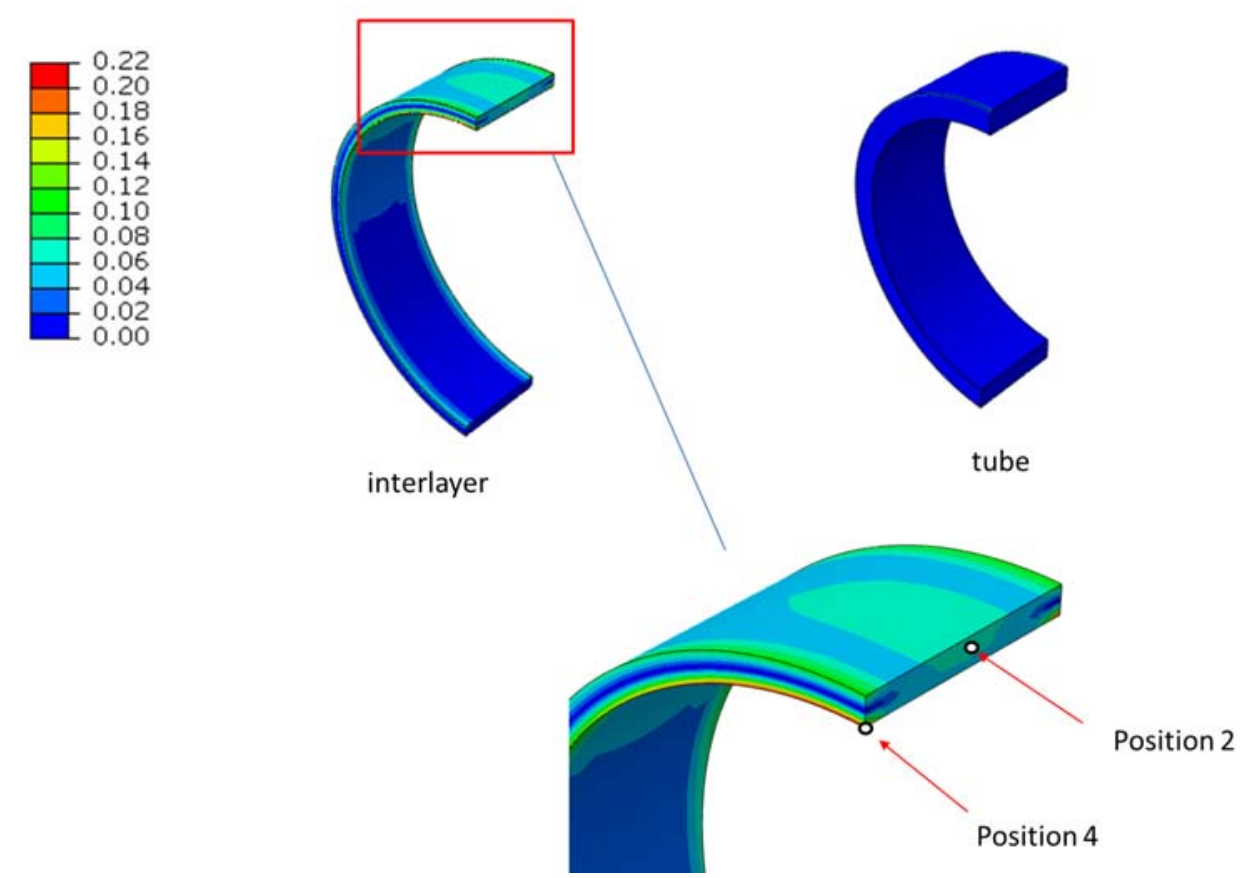

Fig. 11. Accumulated equivalent plastic strain for an $\mathrm{HHF}$ load of $15 \mathrm{MW} / \mathrm{m}^{2}$ and a coolant temperature of $200^{\circ} \mathrm{C}$ at the end of $10^{\text {th }}$ HHF load cycle.

Table 4. Predicted equivalent plastic strain range (\%) and fatigue lifetime ${ }^{a}$ in the copper interlayer at positions 2 and 4 , as shown in Fig. 11]

\begin{tabular}{llll}
\hline \hline coolant temperature & $150^{\circ} \mathrm{C}$ & $200^{\circ} \mathrm{C}$ & $250^{\circ} \mathrm{C}$ \\
\hline HHF loads $\left(\mathrm{MW} / \mathrm{m}^{2}\right)$ & & & \\
\hline Position 2 & & & \\
\hline 10 & $0.15 \backslash 26572$ & $0.14 \backslash 29991$ & $0.11 \backslash 45787$ \\
15 & $0.25 \backslash 10845$ & $0.23 \backslash 12553$ & $0.17 \backslash 21333$ \\
18 & $0.32 \backslash 7032$ & $0.29 \backslash 8358$ & $0.22 \backslash 15371$ \\
\hline \hline Position 4 & & & \\
\hline 10 & $0.47 \backslash 3582$ & $0.46 \backslash 3720$ & $0.33 \backslash 6663$ \\
15 & $0.87 \backslash 1216$ & $0.80 \backslash 1409$ & $0.54 \backslash 2808$ \\
18 & $1.17 \backslash 723$ & $1.03 \backslash 904$ & $0.72 \backslash 1654$ \\
\hline
\end{tabular}

${ }^{a}$ Fatigue lifetime (allowed number of load cycles) was estimated from the reported fatigue data using plastic strain for unirradiated copper in the ITER Material Properties Handbook [14]. 


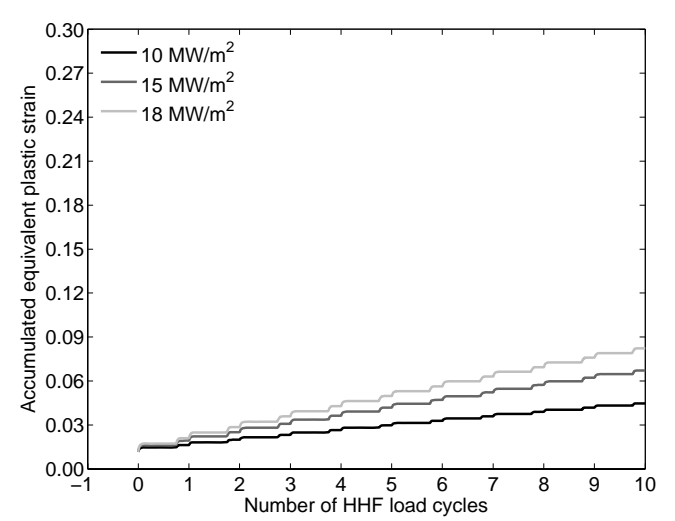

(a) coolant temperature of $150^{\circ} \mathrm{C}$

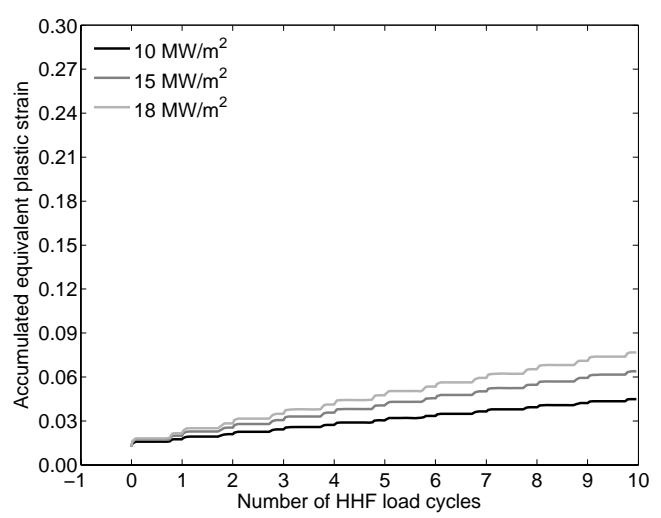

(b) coolant temperature of $200{ }^{\circ} \mathrm{C}$

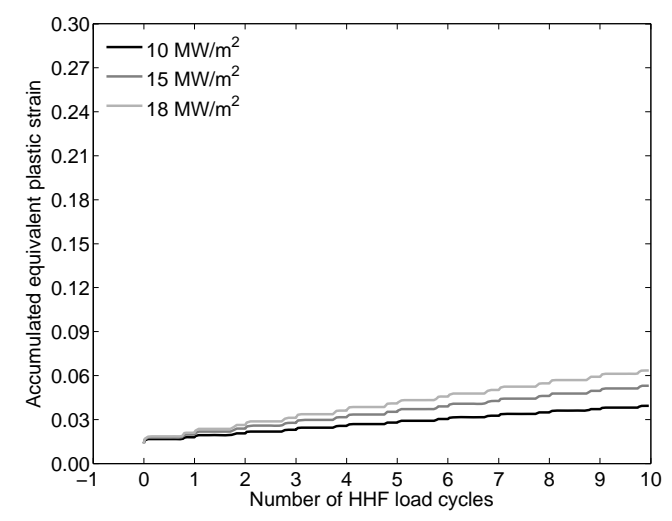

(c) coolant temperature of $250^{\circ} \mathrm{C}$

Fig. 12. Accumulated equivalent plastic strain at position 2, as shown in Fig. 11 


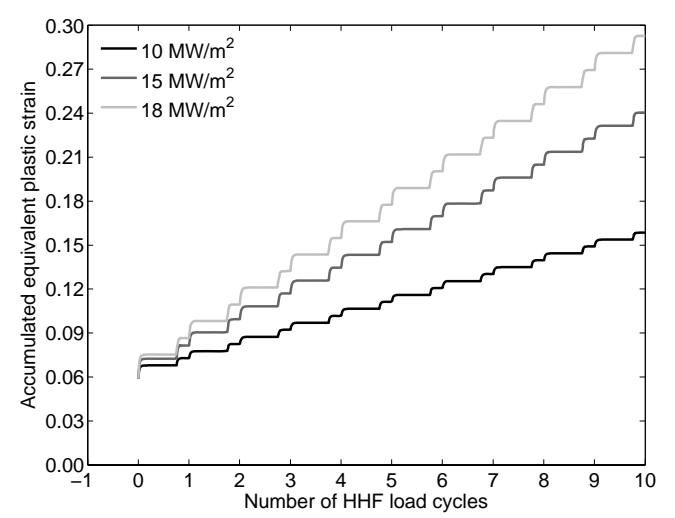

(a) coolant temperature of $150^{\circ} \mathrm{C}$

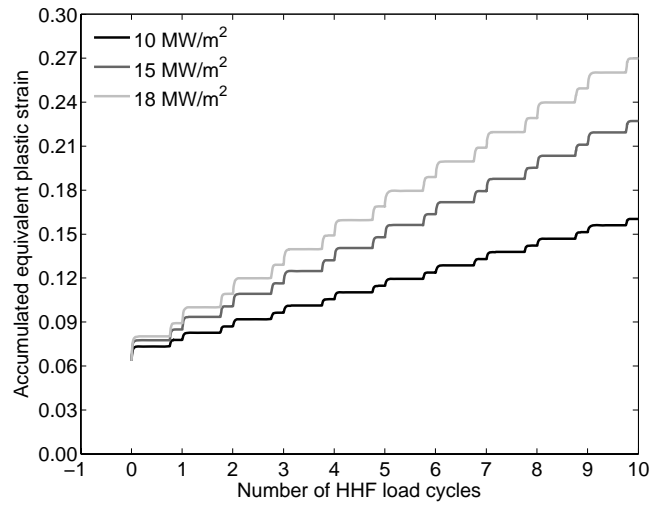

(b) coolant temperature of $200{ }^{\circ} \mathrm{C}$

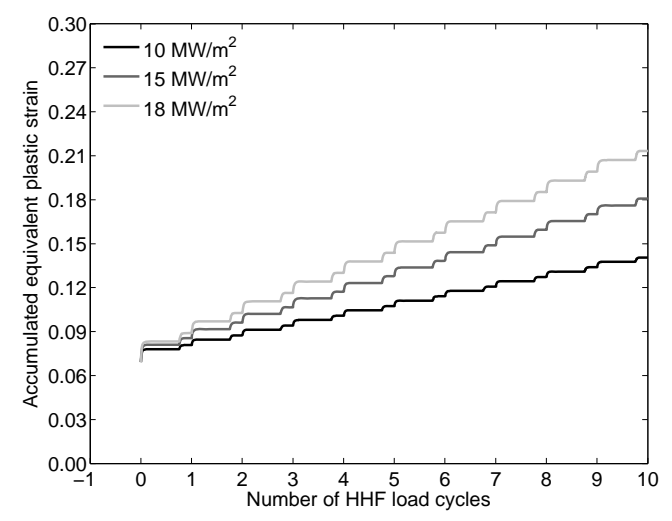

(c) coolant temperature of $250^{\circ} \mathrm{C}$

Fig. 13. Accumulated equivalent plastic strain at position 4, as shown in Fig. 11 


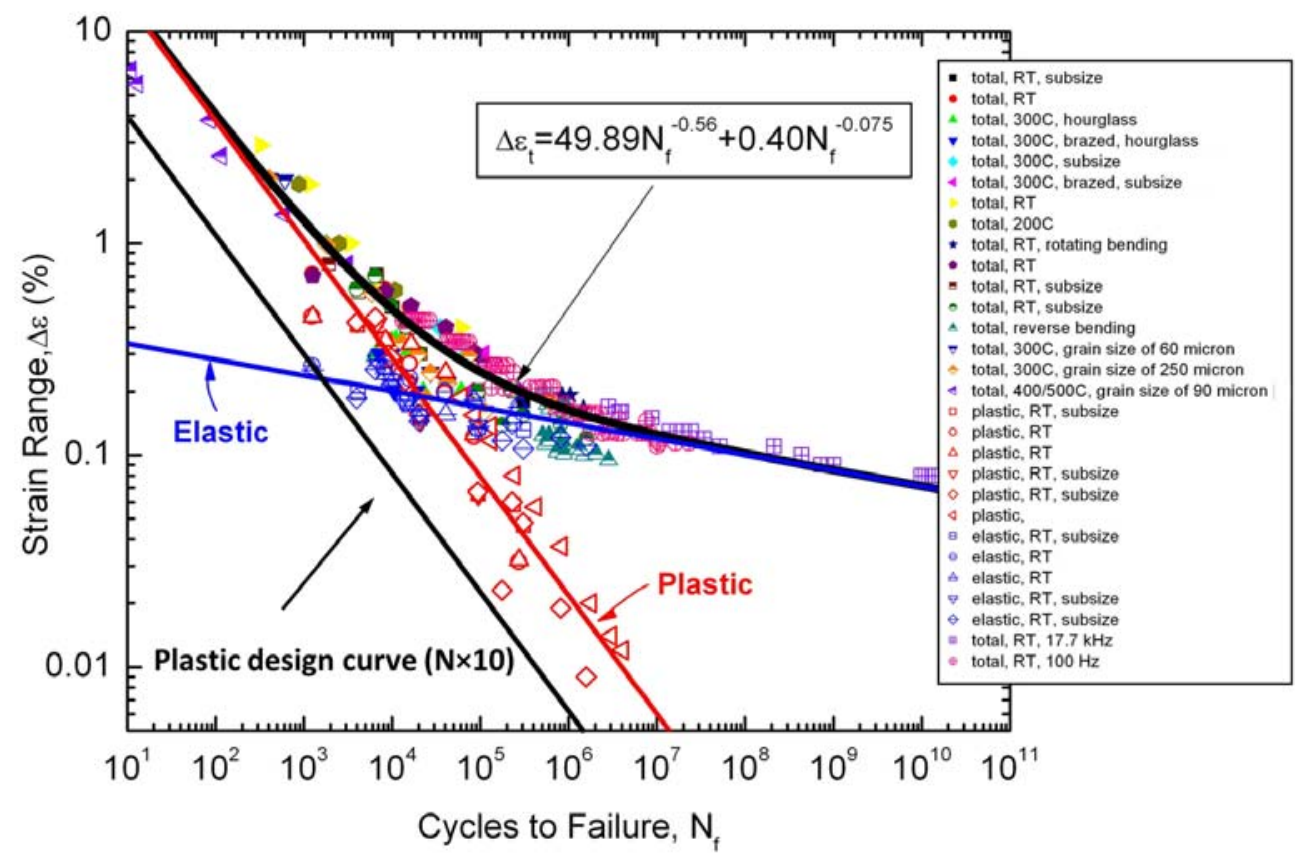

Fig. 14. Experimental fatigue test data [14] of pure copper (OFHC) including both high cycle (elastic) and low cycle (plastic) fatigue failure. The fitted curve bases on a Manson-Coffin type relationship and the design curve for the fatigue lifetime estimation with a safety margin. 


\section{Summary}

In this contribution the LCF behavior of the copper alloy cooling tube and the copper interlayer of an ITER-like divertor target was studied for nine different combinations of loading and cooling conditions relevant to DEMO divertor operation. The LCF lifetime was presented as a function of the loading and cooling conditions considered here by means of cyclic plasticity simulation and using the ITER materials data on LCF. The key findings are as follows:

1. The copper alloy cooling tube initially underwent appreciable plastic flow as a result of thermal expansion mismatch during uniform cooling from the ageing temperature, at which precipitation hardening treatment should take place, but remained completely in the elastic domain in the course of subsequent cyclic HHF loading. It shook down. This means that fatigue failure will not be an issue for the copper alloy tube under an HHF load of up to $18 \mathrm{MW} / \mathrm{m}^{2}$ as long as the initial strength of the copper alloy does not degrade.

2. In contrast, the copper interlayer exhibited significant plastic deformation at the free surface edge of the bond interface adjacent to the cooling tube during individual HHF load cycles. The amplitude of each plastic strain component was readily stabilized after several cycles. The LCF lifetime predictions clearly indicate that lifetime decreases as HHF load is increased or coolant temperature is decreased. HHF loads higher than $15 \mathrm{MW} / \mathrm{m}^{2}$ were predicted to limit the LCF lifetime lower than 3000 load cycles and thus would pose LCF concerns (however, only locally for the edge region).

3. On the other hand, most of the bulk region of the copper interlayer away from the free surface edge did not experience severe plastic fatigue not posing any critical concern. The predicted LCF lifetime reaches at least 7000 load cycles. In case that a conservative fatigue design curve is considered, the estimated design lifetime is possibly not sufficient to meet the design requirement. For instance, if a safety factor of 10 is assumed, then the resulting design lifetime would hardly be able to cover the desired component operation period.

4. The impact of the local LCF damage at the interlayer edge on the structural reliability of the whole target structure needs to be verified by a representative experiment.

\section{Acknowledgement}

The authors are grateful to Mr. Simon McIntosh and Mr. Tom Barrett at Culham Centre for Fusion Energy (CCFE), UK, for providing data on heat transfer coefficients.

\section{References}

[1] European Fusion Development Agreement, A roadmap to the realisation of fusion energy, 2012.

[2] European Fusion Development Agreement, Work plan for the implementation of the fusion roadmap in 2014-2018, 2013.

[3] F. Crescenzi, A. Moriani, S. Roccella, E. Visca, M. Richou, Water-cooled divertor target design study CuCrZr/W monoblock concept, EFDA report: WP13-DAS02-T02-D02, 2013.

[4] ITER Structural Design Criteria for In-vessel Components (SDC-IC), ITER Document No. G 74 MA 8 01-05-28 W0.2, 2008.

[5] J. You, G. Breitbach, Deformation of ductile braze layer in a joint element under cyclic thermal loads, Fusion Eng. Des. 38 (3) (1998) $307-317$.

[6] M. Miskiewicz, J.-H. You, Impact of plastic softening of over-aged CuCrZr alloy heat sink tube on the structural reliability of a plasma-facing component, Fusion Eng. Des. 83 (2008) 66-71.

[7] D. Maisonnier, I. Cook, P. Sardain, R. Andreani, L. D. Pace, R. Forrest, L. Giancarli, S. Hermsmeyer, P. Norajitra, N. Taylor, A conceptual study of commercial fusion power plants, EFDA(05)-27/4.10, 2005.

[8] E. Visca, B. Riccardi, A. Orsini, C. Testani, Manufacturing and testing of monoblock tungsten small-scale mock-ups, Fusion Eng. Des. 56-57 (2001) 343-347.

[9] J. Lemaitre, J.-L. Chaboche, Mechanics of Solid Materials, 1st Edition, Cambridge University Press, 1994.

[10] P. J. Armstrong, C. O. Frederick, A mathematical representation of the multiaxial Bauschinger effect, G.E.G.B. Report $\mathrm{RD} / \mathrm{B} / \mathrm{N}(1966) 731$.

[11] J. Chaboche, Constitutive equations for cyclic plasticity and cyclic viscoplasticity, Int. J. Plast. 5 (1989) $247-302$.

[12] J.-H. You, M. Miskiewicz, Material parameters of copper and $\mathrm{CuCrZr}$ alloy for cyclic plasticity at elevated temperatures, J. Nucl. Mater. 373 (2008) 269-274. 
[13] Abaqus analysis user's manual 6.12., Dassault Systémes Simulia Corp., Providence, RI, USA, 2012.

[14] ITER Material Properties Handbook, ITER Document No.G74 MA 16, 2005.

[15] R. Pitts, S. Carpentier, F. Escourbiac, T. Hirai, V. Komarov, S. Lisgo, A. Kukushkin, A. Loarte, M. Merola, A. S. Naik, R. Mitteau, M. Sugihara, B. Bazylev, P. Stangeby, A full tungsten divertor for ITER: Physics issues and design status, J. Nucl. Mater. 438, Supplement (2013) S48 - S56. 